\title{
"Lições sobre a Morte": o discurso médico na obra de Pedro Nava
}

\author{
"Lessons about Death": the medical discourse in \\ Pedro Nava's work
}

\section{RESUMO}

O propósito deste artigo é examinar os tópicos da morte e da doença na obra do memorialista brasileiro Pedro da Silva Nava (1903-1984), sob perspectiva interdisciplinar. O objetivo é discutir essas temáticas, conforme mencionadas em entrevistas e excertos das Memórias, inclusive escritos históricos e biográficos do autor, por meio da análise dos possíveis discursos que estruturam suas concepções de morte e doença. $O$ argumento central do estudo é que Pedro Nava se refere à morte e à doença no âmbito dos temas prioritários, segundo um modelo médico humanista. $O$ arcabouço teórico deste estudo se baseia em obras que versam sobre os principais discursos contemporâneos relativos à doença e à morte. A análise sugere que Pedro Nava explorou as noções de morte e doença com enfoque humanista e sócio-histórico, utilizando seu conhecimento médico como modelo referencial para criar relatos vívidos e retratos biográficos.

Palavras-chave: História da Medicina - Discurso Médico - Doença como metáfora - Memórias de Pedro Nava - Narrativas sobre doença e morte

\begin{abstract}
The article examines the topics of death and disease in the work of Brazilian author Pedro da Silva Nava (1903-1984), in an interdisciplinary approach. Sources are interviews and excerpts from his Memoirs, historical and biographical writings, through an analysis of the discourses that structure Nava's conceptions of death and disease. The central argument is that Pedro Nava refers to death and disease within the framework of priority themes, according to a humanistic medical model. The theoretical frame for the study is based on works about the contemporary major discourses rises on death and dying. The analysis suggests that Pedro Nava explored the notions of death and disease from a sociological and historical point of view, using his medical knowledge as a framework to create vivid reports and biographical portraits.
\end{abstract}

Keywords: History of Medicine - Medical Discourse - Disease as a metaphor - Memories of Pedro Nava - Narratives about illness and death

* Doutora em História Social pela Universidade de São Paulo. Pesquisadora vinculada ao grupo Variações do Insólito: do mito clássico à modernidade, junto à Universidade Federal da Paraíba (UFPB/CNPq). CV: http://lattes.cnpq.br/9257665714343943 


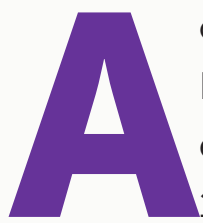

obra de Pedro Nava oferece considerável campo de pesquisa às ciências humanas. Ele escreveu sobre a história da Medicina brasileira e foi um dos pioneiros de sua especialidade, criador da primeira cadeira de Reumatologia do país (Sabino; Neves, 1974). Conforme Vanda Arantes do Vale (2002b, p. 99): "Nava teve ampla atuação como médico e professor, escreveu, aproximadamente, 350 artigos desta área, publicados em revistas especializadas ou apresentados em congressos". A partir dos anos 40 do século XX, vem a público uma série de textos de ordem biográfica e histórica sobre temas médicos - artigos, conferências, crônicas e discursos - itens da revista Brasil Médico Cirúrgico ou das coletâneas Território de Epidauro (1947) e Capítulos da História da Medicina no Brasil (1949), escritos cuja produção o autor justificou na entrevista concedida a Edmílson Caminha, em 1984, publicada mais tarde em Palavra de escritor (1995):

Minha obra médica é bastante grande, tenho algumas centenas de trabalhos publicados. [...] De modo que escrevi minha vida inteira, sempre com a preocupação de escrever bem: nunca assinei trabalho de colaboração que não fosse escrito por mim. Quem bateu a máquina, quem deu forma àquilo fui eu. Tenho dois livros anteriores aos de memória, sobre história da medicina, a que não dou grande valor porque foram feitos às pressas, eu estava interessado num concurso para uma cadeira de história da medicina. São livros fabricados, não foram escritos, como a minha obra memorialística. Nessa eu procuro dar o melhor que posso, o mais trabalhado possivel (Caminha, 1995, p. 45).

Proferido no Real Gabinete Português de Leitura, na cidade do Rio de Janeiro, em 10 de junho de 1961, em comemoração ao Dia de Portugal, o discurso intitulado A Medicina de Os Lusíadas e outros textos (2004), "valeu ao autor uma condecoração do governo lusitano", comentou Paulo Penido (2004, p. 9), presente ao evento na ocasião. Eliane Vasconcellos refere outra parte desse legado, hoje no Rio de Janeiro, como acervo da Fundação Casa de Rui Barbosa, que

reúne, com exclusividade, a produção de Pedro Nava. Inclui manuscritos e textos datilografados, em sua versão definitiva ou em estado de elaboração, além de alguns esboços e notas significativas. As notas esparsas encontram-se catalogadas na série Diversos. Sua produção intelectual subdivide-se em: Artigo, Ata, Biografia, Capítulo de livro, Conto, Discurso, Ensaio, Entrevista, Memória, Nota, Orelha, Poema, Prefácio, Relatório e Sinopse. A subsérie Artigo contém 12 artigos, todos datilografados com emendas e nenhum deles possui outra versão, cinco dos quais, segundo pudemos apurar, haviam sidos publicados (Vasconcellos, 2001, p. 23-24).

Conforme Nísia Trindade Lima (2019), Pedro Nava é lembrado também por "sua defesa de uma medicina humanista, como em $O$ anfiteatro e tantos outros textos igualmente inspiradores". Após mais de meio século dedicado ao exercício da Medicina, surge o projeto 
das Memórias, com Baú de Ossos (1972), Balão Cativo (1973), Chão de Ferro (1976), BeiraMar (1978), Galo-das-Trevas (1981), O Círio Perfeito (1983) e as 36 páginas de Cera das Almas, interrompidas com a morte do autor em 1984, e publicadas em 2006. "Antes disso, Pedro Nava era mais conhecido como médico e amigo de escritores, muitos deles do grupo de Minas Gerais, marcante na literatura brasileira", observou Fernando Neubarth (2003, p. 12).

Entrevistado por Edina Panichi, em 8 de abril de 1984, Pedro Nava mencionou projetos que o atraíam e gostaria de realizar na velhice, tais como "ser mercador de livros raros e velhos" e "ser mercador de gravuras". Para o autor, a opção de escrever memórias significava "retomar a [sua] tradição de mocidade": a literatura. O projeto foi incentivado por escritores importantes:

Quando senti que estava entrando nesse caminho de ficar só, analisando bem, pensei: o que é que vou fazer quando ficar velho, se estiver com a cabeça funcionando direito? [...] Eu tinha cultivado a literatura quando moço. E resolvi fazer uma literatura de velho, que não tinha ideia de expandir. Escrevi como distração, para meus irmãos, coisas que eles não sabiam, mas eu sabia, sobre minha família. Escrevi meu primeiro livro e resolvi mostrar os originais a algumas pessoas que viviam insistindo comigo para escrever memórias [...] E eu tinha dentro da cabeça aquela tentação. Mandei tirar quatro cópias: dei uma ao Drummond, para saber a opinião dele; uma ao Fernando Sabino e outra ao Otto Lara Resende, amigos em quem deposito a maior confiança. [...] E o Fernando Sabino [...] tinha uma editora nesse tempo. [...] E me passou o contrato de edição. Assinei e aí ele fez o corte do meu livro, que tinha inicialmente 600 páginas. [...] Foi dessa maneira que fui para a memória (Panichi, 2003).

Se a resolução primordial do escritor era "fazer uma literatura de velho, que não tinha ideia de expandir" e divulgar para um número maior de leitores, o processo composicional das Memórias, analisado por diversos pesquisadores da obra de Pedro Nava, como Celina Fontenele Garcia (1997), Eneida Maria de Souza (2003) ou Edina Panichi e Miguel Contani (2003), será enriquecido pelo estudo genealógico; pela formação de um variado arquivo pessoal e familiar; pela pesquisa documental e bibliográfica; pela investigação para obter informações de parentes e conhecidos; e por um sistema particular de registrar anotações, desenhos e recortes (de jornais, revistas e gravuras) em fichas e cadernos. "Dei-me conta de que Pedro Nava viera ao longo da vida registrando, em forma de diário, com certa regularidade e meticulosidade, suas viagens e apontamentos que the pareciam de interesse", escreveu Penido (2004, p. 9). A revelação do teor literário dos escritos que originaram Baú de Ossos certamente impulsionou o autor a prosseguir:

Meu plano inicial não era escrever cinco volumes: eu queria escrever um livro de lembranças familiares, de fatos que eu conheci mas meus irmãos ignoravam. Seria um livro clandestino, pra correr dentro da família. Os originais eu dei pra ler ao Fernando Sabino, ao Otto Lara Resende e ao Drummond, e a opinião deles foi que eu deveria continuar no mesmo tom, escrevendo as minhas memórias. Foi o que 
aconteceu. [...] eu pretendia escrever um livro de lembranças familiares, acabei escrevendo, até o momento seis volumes - que são grandes, de trezentas a quinhentas páginas cada um -, onde estou apenas nos meus trinta, trinta e um anos, por aí. Veja como fui levado pelo meu próprio roteiro, pelo que eu queria escrever. Aquilo provocou em mim uma série de caminhos, uma abertura pra novas estradas, uma coisa extraordinária. Foi uma experiência fascinante, essa viagem dentro de mim mesmo. Vi que tinha muita mais coisa pra contar do que eu próprio supunha... (Caminha, 1995, p. 39).

A obra de Pedro Nava compreende longo trabalho arquivístico, referido em entrevistas e exposto nas Memórias, em digressões que elucidam o método composicional e as fontes utilizadas pelo autor. Raquel Beatriz Junqueira Guimarães (2000, p. 25-36) relacionou a função dos arquivos navianos a um dos planos essenciais de sua prosa memorialística, a criação de retratos biográficos: "Nava está ocupado em escrever, desenhar, reescrever, fotografar, de forma a recompor o passado, agregar os diferentes pedaços, colá-los, recompor o mosaico da memória" e da "experiência vivida pelo narrador com os personagens que escolheu desenhar". Tal reflexão pode ser ilustrada por este excerto de Beira-Mar, referente à época em que o autor viveu as primeiras experiências profissionais durante o curso de Medicina, em Belo Horizonte:

Foi quando vi que não estava só e que duas sombras - uma toda de negro e a outra vestida de amarelo me esperavam no corredor. Mais que o Dante descendo aos Infernos eu ia ser guiado dali por diante por dois virgílios - a morte e a doença rindo de mim e zombando de todos os esforços. Eu entro quando a vida saiu e assim vocês não têm nenhum poder sobre mim - ouvi da primeira. Olha minha complexidade e a minha perfeição só semelhantes às da Saúde, convence-te de que eu também sou fenômeno de comissão e não de omissão, pertenço à Natureza. Agora toca em mim - disse a outra - trata, mas lembra-te de Lucas que também era médico - Medice, cura te ipsum... Fechei os olhos encadeado de tanta verdade e quando os abri não vi mais nada. Mas tinha a sensação de duas companhias - corvos que me deixariam nunca mais. Foi com elas que eu sentia sem ver, como percebemos o ladrão no escuro de breu - que entrei na clínica cirúrgica (Nava, 1979, p. 358).

A morte e a doença são tópicos que conciliam inúmeras perspectivas, imagens, temas e referências autobiográficas, históricas e literárias nas Memórias. Edina Panichi (2007, p. 46) analisou a morte na acepção de "tema constante" e "personagem, quase protagonista" na obra de Pedro Nava, comparando passagens de poemas, memórias e entrevistas do autor:

Em seus escritos ela ocupa lugar essencial, mas não apenas como a presença de uma realidade cotidiana na vida de um médico. Ao contrário, a morte se insinua em todos os espaços de sua construção e é um dos núcleos em torno do qual se organizam vivíssimas emoções (Panichi, 2007, p. 46). 
Já "a tematização da doença nos escritos de Nava", considerando "o papel social e econômico da Medicina e as discussões e estratégias que a envolveram no período" foi discutida por Vale (2006, p. 133).

Ao examinar a memorialística de Pedro Nava "em seu contexto social, e buscar como esta 'constrói ou representa a realidade', tratando a Literatura como testemunho histórico e considerando a obra como 'evidência histórica objetivamente determinada'", Vale (2002a; 2002b, p. 104) apreendeu o tema da doença em certas questões, como o exercício da Medicina no Brasil colonial e republicano, a história das instituições médicas brasileiras (associações, faculdades e secretarias de saúde) e o início das políticas saneadoras de Medicina preventiva:

Médicos, associações de classe e seus representantes discutiram as doenças, notadamente as "febres" e propuseram medidas saneadoras e de intervenção no espaço físico das cidades brasileiras e de sua população. Nava em Baú de ossos, ao tratar da questão em Juiz de Fora, criou um documento sobre os significados e objetivos da atuação médica do período (Vale, 2002a, p. 113).

Sob enfoques diversos, como do ensaio, biografia, crônica histórica e de costumes, a memorialística de Pedro Nava está imbuída de referências à Medicina, com discurso análogo ao de seus escritos iniciais. Abordados com vasto repertório de leituras, pesquisas acadêmicas, experiência pessoal e profissional, morte e doença são tópicos fecundos em sua obra, pontuados de associações com a literatura e a história da arte. Para sondá-los, Pedro Nava (1974, p. 162) recorreria ainda ao acervo documental pessoal e familiar: "Somos os arquivistas da família. [...] conhecimento que eu cultivo do ponto de vista da zootecnia e da fuga para o convívio dos mortos" - talvez cultivasse do ponto de vista clínico também, como sugere um trecho biográfico de Chão de Ferro sobre o casal Antônio e Alice Nava Salles: "Quando o arquivo de Antônio Salles veio para minhas mãos lá descobri assentamentos de cuidados médicos dados a minha tia pelo Dr. Lincoln de Araújo. Era terapêutica para esterilidade. Falhou" (Nava, 1976, p. 77).

A análise comparativa de entrevistas do autor e de pessoas de seu convívio esclareceria temas como suicídio, velhice e conduta profissional, associados à doença e morte:

Nós ficamos falando, discutindo os aspectos da questão, achando que os médicos se suicidam para evitar o sofrimento, sobretudo do câncer, já que eles conhecem como é nos outros. Aí, começamos a discutir métodos de suicídio. E o Nava já tinha dado entrevista dizendo que conforme o temperamento o sujeito ou se enforca, ou se atira de uma janela ou dá um tiro na cabeça, ou toma veneno (Penido, 1998, p. 33).

Este artigo analisa os temas da morte e da doença, conforme referidos em excertos das Memórias, entrevistas e escritos histórico-biográficos de Pedro Nava. O objetivo é discutir, sob enfoque interdisciplinar, o discurso que reflete a visão do profissional médico sobre tais temáticas e as imagens mobilizadas para seu registro. Nesse intuito, a parte inicial do estudo apresenta alguns discursos sobre a morte e a doença, observados na sociedade contemporânea 
e analisados por teóricos da sociologia, história cultural e social, inclusive o campo médico. A seguir, o tópico comenta descrições, digressões, relatos e retratos biográficos em que o escritor abordou os temas da doença e da morte. A última parte alude às principais características do modelo médico humanista em uníssono com declarações e passagens da obra naviana.

\section{Discursos modernos sobre a morte}

De acordo com o sociólogo Tony Walter (1994), a cultura ocidental produziu durante o século XX uma literatura sobre a morte, o morrer e o luto, alicerçada no pensamento de uma sociedade cujo discurso público sobre a morte é dominado pela lógica de uma Medicina e de profissionais de diversas áreas, que prestam assistência ao final da vida, ao morto e sua família.

Ao assimilar a experiência pessoal, o discurso institucional contemporâneo fez-se concludente, para determinar como o indivíduo deve se sentir e proceder diante de perdas ou da própria morte. Concomitante a esse discurso, existe um segmento no pensamento atual, voltado à mídia, à rotina hospitalar e ao treinamento de equipes médicas, que privilegia a emoção pessoal na esfera pública. Porém, a tendência de celebrar o privado colapsou a distinção entre o público e o particular, tornando as emoções do paciente e da família uma preocupação para o médico. Por conseguinte, priorizar as emoções do moribundo e da pessoa enlutada gerou a possibilidade de o doente optar por terapêuticas ajustadas a seus valores ou com as quais se sinta confortável, em detrimento da conduta julgada mais efetiva pelo médico na ocasião (Walter, 1994, p. 41).

Em "Morte e luto: competências dos profissionais", Nazaré Hayasida, Raquel Helena Assayag, Isa Figueira e Margarida Gaspar Matos (2014) compararam formas representativas de ambos os modelos de discurso médico, respectivos à doença e à morte abordados por Walter evidenciando o alcance de assistência da Medicina em situações de doenças crônicas ou fatais:

A desmistificação do tema da morte auxilia os profissionais a conviver melhor com aqueles pacientes que não respondem mais aos tratamentos que visam a cura, permitindo à equipe aceitar melhor seus próprios limites de intervenção e dedicar-se a outros tipos de cuidado, como o paliativo. Os cuidados paliativos (CP) surgiram como uma necessidade da sociedade que perdeu as infraestruturas que the permitiam cuidar dos doentes graves e dependentes que requeriam cuidados constantes, sem que necessariamente a morte estivesse próxima [...]. Há pacientes que preferem morrer em casa a receber cuidados em atendimento hospitalar de alta qualidade, bem como o apoio de que necessitam para alcançar uma "boa morte" (ou seja, uma morte acompanhada de dignidade e sem sofrimento). [...] Transferir um paciente do hospital para casa, sobretudo nos municípios afastados dos grandes centros, dificulta a otimização da eficácia dos serviços, sem uma organização que dê apoio efetivo ao paciente e à família em caso de câncer (Hayasida; Assayag; Figueira; Matos, 2014, p. 114).

Para Jonathan Dollimore (1998, p. 127), qualquer constructo social, da religião, poesia 
à psicanálise e tecnologia médica, surge em resposta à força desordenadora da morte. Um discurso cultural relativo ao adoecimento afirma a doença como metáfora. Susan Sontag descreveu a repercussão social da doença e seu enfoque como indício de má conduta, degradação física e mental, causa de anátema, banimento, catarse e execração pública:

No ponto de vista pré-moderno sobre a doença, o papel da personalidade restringia-se ao comportamento da pessoa após o início da enfermidade. Como qualquer situação extrema, a doença temida revela tanto o melhor como o pior da pessoa. Porém as explicações usuais das epidemias tratam sobretudo do efeito devastador da doença sobre a personalidade. Quanto mais fraco for o preconceito do cronista de que a doença é o castigo por alguma iniquidade, maior a probabilidade de que a explicação enfatize a corrupção moral que a disseminação da doença tornou manifesta. Mesmo que não seja entendida como um julgamento sobre a comunidade, a doença torna-se isso retroativamente -, porquanto desencadeia uma inexorável derrocada da moral e dos costumes. Tucídides relata como a peste que irrompeu em Atenas, em 430 a.C., espalhou a desordem e a ilegalidade ("o gozo do momento tomou o lugar tanto da honra quanto da experiência") e corrompeu até o idioma (Sontag, 2007, p. 27).

"O conceito de corpo social é um conceito histórico", afirmou Moacyr Scliar (2002, p. 19), que analisou algumas modalidades culturais de discursos clínicos, institucionais e sociais, sobre a "trajetória que é a história natural da enfermidade", do "período pré-patogênico até o desfecho final (cura, morte, sequela)". Ao referir historicamente as teorias sociológicas do organicismo, o autor afirma:

A ênfase dada ao papel social e comunitário explica o metafórico conceito de saúde pública como medicina do corpo social - a saúde pública só pode surgir quando a sociedade atingiu um grau de organização suficiente para ser caracterizada como "corpo" (Scliar, 2002, p. 5-6).

Um conjunto de fatores é responsável por proteger o corpo social de situações que o tornem disfuncional e fragmentado:

Para antigos hebreus, a doença não era devida a ação de demônios, ou
maus espíritos, mas representava, de qualquer modo, um sinal da cólera
divina diante dos pecados humanos. Diz a Bíblia: "Eu sou o Senhor, e é
saúde que te trago"(Êxodo, 15-26): "De Deus vem toda a cura" (Eclesiastes,
38, 1-9). A doença era, pois, sinal de desobediência ao mandamento
divino. A enfermidade proclamava o pecado, frequentemente em forma
visivel, como no caso da lepra. Nestes casos, o doente era isolado até a
cura (Scliar, 2002, p. 5-6).

Segundo Walter (2017, p. 16), durante séculos coube à religião orientar simbologias, atitudes e ações rituais que investissem de significado a morte. Hoje, por contraste, o "leito 
de morte" é circundado por questionamentos e tentativas de atribuir sentido a certos dilemas; pela anomia e incerteza sobre a melhor conduta. Uma forte crença ou filosofia, seja religiosa ou ateísta, ajudaria o moribundo e o enlutado. Com o processo de secularização estendido por uma geração ou duas, hospitais, igrejas e tampouco aqueles que perderam a fé professada na infância poderiam oferecer o suporte cultural e emocional esperado por pessoas mais velhas.

O sociólogo britânico Clive Seale (1995) analisou o modo como as pessoas buscavam imbuir de significado a morte e os cuidados relativos ao morrer. $O$ estudo baseou-se em uma pesquisa feita no Reino Unido, na última década do século $X X$, compreendendo relatos de 250 pessoas que assistiram alguém que havia falecido. $O$ resultado da análise contraria a ideia da negação da morte ser disseminada quando a religião não oferece aos circunstantes uma narrativa significativa sobre quem está morrendo. Pessoas leigas podem contar com roteiros (scripts) promovidos por especialistas culturais para proclamar uma identidade heroica em face da morte. A situação envolveria uma batalha interna e externa, a fim de obter conhecimentos, oportunidade de demonstrar coragem e um beatífico estado emocional de acompanhamento em que participam "cuidadores" e moribundos. Ao contrário de modalidades mais tradicionais de heroísmo, esse roteiro não celebra unicamente qualidades masculinas e inclui formas femininas heroicas de cuidado e expressão emocional.

Stefano Allievi (2014, p. 65) recordou o termo "morte proibida", definido por Phillipe Ariès (2003) em sua descrição das fases da história da morte no Ocidente. Para Allievi, a época atual inauguraria uma nova fase na história da morte. Esta não é mais negada ou expressamente proibida. Em uníssono com Walter (1994), que denominou de "reavivamento da morte" ao fenômeno contemporâneo de proliferação de produção bibliográfica sobre a morte e o luto, Allievi arguiu que o discurso sobre a morte subsiste e desperta sempre interesse, por duas razões opostas. De um lado, a morte é explicitamente abordada, a fim de ser combatida: este seria o discurso da "morte rinviata" (morte prorrogada). Do outro, no discurso da "morte ritrovata" (morte reencontrada), a morte é abordada como evento natural, aceitável, até esperado, inclusive, a despeito ou contra a ciência médica empenhada em adiá-la por meio de uso da tecnologia.

"A morte da morte: como a medicina biotecnológica vai transformar profundamente a humanidade" (2013), do médico francês Laurent Alexandre, relaciona os desafios da medicina preventiva a questões culturais, à cibernética e à ecologia. "A morte da morte: a possibilidade científica da imortalidade" (2019), obra do matemático David Wood e de José Luis Cordeiro, engenheiro venezuelano formado pelo Massachusetts Institute of Technology (MIT), aborda a "interrupção da velhice", pensada como doença. Os argumentos e dados amparam-se nas ideias do filósofo Raymond Kurtzweil e nos "recursos médicos e computacionais que já ajudam a prolongar a vida e prometem transformar a morte em um mal evitável" (Vilardaga, 2019).

Assim, de um lado, um potente impulso tecnológico ante uma "sociedade pósmortal" (Lafontaine, 2008), condição a que Remo Bodei (2010, p. 66) nomeou de "a época do antidestino", caracterizada pela obsessão cultural, pela implementação desmesurada de meios econômicos e científicos, orientados aos seguintes fins: adiar tecnicamente a morte; viver sem envelhecer; reduzir ou reverter, ao máximo, tanto as consequências do envelhecimento como 
sua aparência, adotando o padrão estético veiculado pela mídia e pela publicidade; e prolongar indefinidamente a vida. Allievi (2014, p. 65-66) considera que tal enfoque se apoia em vários níveis da tecnociência: da medicina preventiva à curativa, da genética à medicina regeneradora, da nanotecnologia ao transplante, na convicção de alcançar um ideal de imortalidade.

Pragmático, com base em pesquisas que agregam vasto complexo científico industrial, dotado de imensos recursos e vasto consenso cultural, ao menos no Ocidente, esse discurso se endereça à sociedade, em rejeição à ideia expressa de morte, não só a favor de seu contínuo e eficaz distanciamento. Mas ainda permanecem controversas e obscuras para os avanços do conhecimento científico "as consequências éticas e sociais desse marcado desejo de conquistar cientificamente a morte, para viver sem envelhecer e ainda prolongar indefinidamente a vida" (Lafontaine, 2009, p. 297).

Simultâneo a essa potente e difusível tendência, emerge o discurso que propõe nova reflexão sobre a morte e sua progressiva neo-humanização em seu ressurgimento, por assim dizer (que não é, historicamente, uma novidade, mas um retorno) no âmbito do que deve ser pensado e experienciado, do que é sentido e visto coletivamente, não somente na esfera individual. Allievi $(2014$, p. 66) reconhece ao menos duas razões para essa contratendência.

A primeira razão, embora exclua o debate acadêmico, assoma no espaço público do debate bioético, pela exposição de casos e histórias individuais altamente midiatizadas e politizadas, que atingem ampla fatia da opinião pública, reportando-se a decisões individuais significativas e particularmente difíceis, segundo o clássico mecanismo da empatia: o que eu faria se estivesse em seu lugar? A segunda razão seria a progressiva pluralização cultural e religiosa da sociedade, com o retorno na esfera pública do modo de sentir e de pensar que o saber biomédico - que fora capaz de influenciar a cultura religiosa e de reduzi-la à própria razão e, mais em geral, a cultura e o espírito do tempo - havia marginalizado no passado. Essa tendência foi assimilada com o aumento da literatura autobiográfica e diarística nos anos 80.

As Memórias relatam várias experiências e reflexões íntimas de Pedro Nava, ora em digressões confessionais, ora com o artifício da narrativa em terceira pessoa. Os relatos sobre a morte e a doença não se endereçam a um público especializado, mas neles se identifica a cultura e o saber médico, tornados matéria da narração, de forma autobiográfica e sóciohistórica.

\section{As companheiras "do Tempo e de sua atividade paciente"}

Nas Memórias, a primeira alusão à doença consta nas páginas iniciais de Baú de Ossos, implícita no retrato sócio-histórico que o escritor esboça da cidade de Juiz de Fora, tendo por ponto de partida a Rua Halfeld. Relacionada à melancolia, à margem direita desta rua

estão a Câmara; o Fórum; a Academia de Comércio, com seus padres; o Stella Matutina, com suas freiras; a Matriz, com suas irmandades; a Santa Casa de Misericórdia, com seus provedores; a Cadeia, com seus presos (testemunhas de Deus - contraste das virtudes do Justo) - toda uma 
estrutura social bem pensante e cafardenta que, se pudesse amordaçar a vida e suprimir o sexo, não ficaria satisfeita e trataria ainda, como na frase de Rui Barbosa, de forrar de lã o espaço e caiar a natureza de ocre. [...] A densa melancolia dessas instituições transmitia-se aos que as mantinham - criação agindo poderosamente sobre os criadores e seus descendentes [...] Honrados, taciturnos, caridosos, castos e temperantes, esses ricos homens traziam geralmente na fisionomia um ar de fadiga, de contenção e de contraída tristeza [...] Já a margem esquerda da Rua Halfeld marcava o começo de uma cidade mais alegre, mais livre, mais despreocupada e mais revolucionária. O Juiz de Fora projetado no trecho da Rua Direita que se dirigia para as que conduziam a Mariano Procópio era, por força do que continha, naturalmente oposto e inconscientemente rebelde ao alto dos Passos. Nele estavam o Parque Halfeld e o Largo do Riachuelo, onde a escuridão noturna e a solidão favoreciam a pouca vergonha. Esta era mais desoladora ainda nas vizinhanças da linha férrea, onde a Rua Hipólito Caron era o centro do deboche e um viveiro de treponemas (Nava, 1974, p. 14).

Se "a densa melancolia" não prevalece na margem esquerda da cidade, esta apreende uma questão de saúde pública. No excerto, a alusão ao Treponema pallidum, agente etiológico da sífilis, possui conotação histórica e social. Sérgio Carrara (1996, p. 163-164, grifo do autor) abordou as políticas de saneamento instituídas entre fins do século XIX e início do século XX, para descrever a "chamada luta antivenérea", que adotaria um discurso moralizador em relação ao doente, como o parecer do médico Claudemiro Augusto de Morais Caldas (1846-1883):

a sífilis não se circunscreve ou limita os seus insultos àqueles que, no redemoinhar das orgias, celebram a apoteose da carne (...) [como] o sibarita que, colhendo nas saturnais do prazer o merecido castigo de sua lubricidade, leva consigo por toda a parte, como foco ambulante de infecção, o germen de lesões cujos efeitos horriveis repercutem-se não só por toda a economia, como ainda transmitem-se por via da geração (Caldas, 1866, p. 55 Apud Carrara, 1996, p. 146).

Os sifilógrafos da época reivindicaram sua autoridade a fim de combater o estigma da doença e obter a cooperação de outros profissionais. Para atenuar a marginalização do enfermo, sem prejuízo da moral sexual vigente, recorreram a "uma espécie de 'sociologia' da sífilis", que observava o contexto socioambiental em que ela se manifestava e os fatores implicados no processo epidemiológico. Na tradição higienista do século XIX, as causas secundárias da expansão da doença pressupunham razões climáticas, culturais, econômicas, jurídicas, políticas e raciais, envoltas na organização social.

Por isso mesmo, no que dizia respeito à ação pública, principalmente profilática, ou preventiva, os médicos sempre reconheceram [...] a sífilis como objeto que devia interessar legitimamente a "moralistas", "sexólogos", "pedagogos", "juristas" e "sociólogos", cuja ação conjunta reivindicavam (Carrara, 1996, p. 164). 
Dividindo espaço com o "deboche" e o "viveiro de treponemas", segundo Pedro Nava (1974, p. 15): "Havia fábricas, como a do Eugeninho Teixeira Leite, e a Mecânica, onde homens opacos se entregavam a um trabalho que começava cedo e acabava tarde no meio de apitos de máquinas e das palmadas dos couros nas polias"; "fábricas onde os descontentes queriam ganhar mais do que precisavam"; "o Cinema Farol e o Politeama onde se tentavam timidamente os ensaios precursores da bolina"; "bordéis"; locais como "[...] a Cervejaria Weiss animada por Brant Horta, Amanajós de Araújo e Celso d'Ávila com guitarras, descantes, declamação de versalhada e as chegadas dos tílburis carregados de 'mulheres damas'".

Segundo Carrara (1996, p. 125, grifo do autor), "desde (pelo menos) finais do século XIX, era comum considerar-se todo brasileiro como sifilítico [...] [e] os brasileiros particularmente excessivos sexualmente", afeitos à "devassidão", "luxúria" e "sensualismo" - "tal crença remonta ao início da empresa colonial" e foi integrada, entre fins do século XIX e a primeira metade do XX, à literatura desenvolvida "cientificamente" por intelectuais brasileiros, tais como Gilberto Freyre, Nina Rodrigues, Paulo Prado, Pires de Almeida e Afonso Arinos de Melo Franco, empenhados em esclarecer "a nossa formação social e as razões de suas mazelas".

Tal modelo de análise social parece estar implícito na descrição das margens esquerda e direita da Rua Halfeld, sugerindo certa relação de causa e efeito entre o estilo de vida do meio social e a doença correspondente. Na descrição estaria igualmente implícito o tipo de discurso científico moralizante da época, cuja censura Pedro Nava inverte, com uma nota de humor sobre

os que levavam vida impenetrável em suas casas trancadas, frequentandose só nos apostolados e nas empresas, não conhecendo as passeatas noturnas da Rua Halfeld, as cervejadas alegres do Foltram [...] o Cinema Farol, o Politeama e o Clube Juiz de Fora londe estalavam carambolas de bilhar e o leque ciumento brandido por D. Cecinha Valadares na cara das sirigaitas que atiçavam o Chico Labareda) (Nava, 1974, p. 14).

Permeada pela objetividade do discurso científico, a delimitação "clínica" da doença em algumas descrições físicas evoca o Naturalismo e o conhecimento do paleopatologista:

De Dona Joana Maria da Conceição ficou um daguerreotipo, ainda dos feitos em chapa de metal, e que pelas vestimentas eu coloco cerca dos quarenta do século passado. De touca e fichu, era uma velha fisicamente horrenda. Tinha a cara quadrada, as maçãs salientes, o queixo prognata, as sobrancelhas muito levantadas para fora, descendo para a raiz nasal - prolongando-se em linha de ouro com os vincos que the punham a boca funda, entre parênteses. Estrabismo divergente e expressão, apesar de tudo, bondosa. Cabeça metida de tronco adentro e este, tão empilhado, que a velha parecia estar sentada, não com os ísquions, mas com as omoplatas. Saía daí um braço imenso e esticado que precisava subir numa rampa de quarenta e cinco graus para atingir o ombro da filha que a ladeava - uma figura de pau, toda em ângulos e quinas, parecendo feita a machado. Aquela postura da tataravó é dessas que fabricam o mal de Pott, as escolioses graves, as grandes platispondilias (Nava, 1974, p. 170). 
Alguns retratos biográficos feitos por Pedro Nava distinguem-se pelo traço romanesco que Antonio Candido (1989, p. 214) reconheceu nas Memórias, que poderiam ser lidas "como se fossem ficção, porque são de fato poderosamente ficcionais a força da caracterização e a disposição imaginosa dos acontecimentos que, mesmo quando documentados no ponto de partida, são tratados com o tipo de fantasia que distingue o romancista". Em O Círio Perfeito, narrado em terceira pessoa, Pedro Nava (1983, p. 102), identificado pelo nome de Egon, enamora-se da jovem Lenora, sem saber que ela está muito doente. "Só em 1977 por intermédio de um primo de Lenora o Egon foi informado de que quando ela tinha se matado já estava condenada. la viver só mais uns poucos meses pois fora-lhe diagnosticada uma leucemia". Para descrever os sinais e sintomas da doença de Lenora, o autor os relaciona à beleza da moça:

No dia seguinte o Egon ia para a casa da namorada numa angústia, numa premonição. Dormira mal, pensando nos dois dias de febrinha e da canseira de que ela se queixara. Mas não. Seria nada: ela era uma moça tão bem constituída que era impossível que sua beleza e suas proporções não fossem sinais de uma higidez perfeita. A doença envilece e acaba tornando feias as pessoas mais belas, e ali o que havia era mesmo o que ele dissera - gripe mal curada. Sua própria palidez era um encanto a mais e não doença - era mesmo assim, escultural e de marfim (Nava, 1983, p. 82).

A noção de doença como princípio desorganizador da imagem corporal, observável na descrição do retrato de Dona Joana Maria da Conceição não se verifica na caracterização da imagem de Lenora. Na passagem, a crônica das relações íntimas une, aos tópicos da medicina, da morte e da doença, outro tema caro à prosa naviana, citado na entrevista a Edmílson Caminha:

Tenho uma verdadeira paixão pela forma, pelo mundo plástico, acho uma coisa fabulosa, a contemplação da natureza. E, dentro dela, o ser vivo, o ser humano, o homem, a mulher, na sua beleza: é uma das coisas mais esplendorosas que há no universo (Caminha, 1995, p. 47).

Na referência a Edgar Allan Poe, combinam-se os temas da beleza, juventude, doença, morte e luto amoroso. "O nome real dela não era Lenora, mas Zilah Pinheiro Chagas" (Penido, 1998, p. 21). Pedro Nava ocultou a identidade da moça sob o título de um conto e de um poema de Allan Poe, mas a referência estende-se à conhecida citação do escritor em "A Filosofia da Composição" (1846):

"De todos os temas melancólicos, qual, segundo a compreensão universal da humanidade é o mais melancólico?" A Morte - foi a resposta evidente. "E quando - insisti esse mais melancólico dos temas se torna o mais poético?" Pelo que já explanei, um tanto prolongadamente, a resposta também aí era evidente: "Quando ele se alia, mais de perto, 
à Beleza; a morte, pois, de uma bela mulher é, inquestionavelmente, o tema mais poético do mundo e, igualmente, a boca mais capaz de desenvolver tal tema é a de um amante despojado de seu amor." Tinha, pois, de combinar as duas ideias (Poe, 2000, p. 410).

Transcreve-se aqui na grafia original da época, a nota publicada no jornal $A$ Noite, de 31 de maio de 1931, referente à morte de Zilah Pinheiro Chagas. "Um facto doloroso: uma filha do Sr. Djalma Pinheiro Chagas morreu em consequência de um tiro":

Cerca das 19 horas de hontem, verificou-se, na residencia do Sr. Djalma Pinheiro Chagas, á rua Xavier da Silveira, 85, em Copacabana, um facto profundamente doloroso. A senhorita Zillah, de 17 annos, sua filha, tendo sido atingida por uma bala, teve morte quasi instantanea. Tudo indicava, como informam os parentes da joven, que se trata de um accidente. A familia, ao ouvir o estampido forte e alarmante, correu ao commodo de onde partira, deparando, então, prostrada, e com as vestes tintas de sangue, a desditosa senhorita. Segurava ella, na ocasião, uma arma, ainda fumegante. Teria a victima, manejando-a, dado ao gatilho, inadvertidamente. Logo que se deu tão triste facto a Assistencia Municipal foi solicitada. A ambulância do Posto Central não se fez demorar, mas o medico nada pôde fazer em beneficio da senhorita Zilah Pinheiro Chagas. O cadaver ficou na residência da família, de onde sairá para ser dado á sepultura. Tão dolorosa occorrencia levou á residência da família Pinheiro Chagas muitas pessoas das suas relações de amizade que deploravam o succedido. ${ }^{1}$

É provável que o obituário da jovem, publicado nessa edição do jornal $A$ Noite, tenha sido lido e arquivado pelo memorialista. Ao referir a versão que ouviu de uma prima de Zilah, Pedro Nava (1983, p. 97) escreveu: "Concluíram que ela abrira a gaveta para tirar o remédio, vira o revólver e não hesitara. Deve ser verdade porque o calvário para o suicida é arranjar o revólver, providenciar o veneno, pendurar a corda no gancho, sentar-se no peitoril da janela".

Na mesma página em que se lê sobre o falecimento de Zilah consta o registro da morte de um "jovem suicida" de 21 anos, por envenenamento com "acido phenico"; as tentativas de suicídio de um padeiro de 29 anos, por ingestão de "creolina", e de uma mulher, "casada e contando 23 annos de edade" que, "julgando que o único remédio para o mal que a acabrunhava era o suicídio, apanhou um vidro de lysol e ingeriu um pouco do líquido"2 além da tentativa de suicídio de um operário de 37 anos, que "recolhendo-se aos seus aposentos, ahi despejou querosene às vestes, ateando-lhes fogo, em seguida". ${ }^{3}$

Neste excerto de Baú de Ossos sobre o médico Francisco de Castro (1857-1901), Pedro

1 UM FACTO doloroso. A Noite, Rio de Janeiro, ano 21, n. 6994, 31 maio 1931. Caderno Última Hora, p. 3. Disponível em: <http://memoria.bn.br/DocReader/Hotpage/HotpageBN.aspx?bib=348970_03\&pagfis=4505\&url=http:// memoria.bn.br/docreader\#>. Acesso em: 10 jan. 2020.

2 POR DESGOSTOS íntimos... A Noite, Rio de Janeiro, ano 21, n. 6994, 31 maio 1931. Caderno Última Hora, p. 3. Disponível em: <http://memoria.bn.br/DocReader/Hotpage/HotpageBN. aspx?bib=348970_03\&pagfis=4505\&url=http://memoria.bn.br/docreader\#>. Acesso em: 10 jan. 2020.

3 VIA fantasmas por toda a parte! A Noite, Rio de Janeiro, ano 21, n. 6994, 31 maio 1931. Caderno Última Hora, p. 3. Disponível em: <http://memoria.bn.br/DocReader/Hotpage/HotpageBN. aspx?bib=348970_03\&pagfis=4505\&url=http://memoria.bn.br/docreader\#>. Acesso em: 10 jan. 2020. 
Nava relacionou o tipo de suicídio a questões comportamentais, com exemplos evocativos dos casos citados na página d'A Noite em que foi noticiada a tragédia da família Pinheiro Chagas: Quando [...] Francisco de Castro morre a 11 de outubro de 1901 - criouse a lenda do seu suicídio. Ulcerado pelo que ouvira dos discípulos, ter-se-ia inoculado uma cultura de bacilos pestosos. Não, não e não. Isso não é verdade. Posso atestar, sem ser contemporâneo, pelo que, separadamente, Afonso Arinos de Melo Franco e eu ouvimos de Aloysio de Castro. [...] O bravo Castro nunca seria de fugir pelo suicídio [...]. Demais a mais, assim como as histéricas se matam com o primeiro desinfetante à mão; os impulsivos, se defenestrando; os exibicionistas, ateando fogo às vestes; os bravos, à bala; os neurastênicos, se enforcando - os médicos se destroem pelo veneno (que ainda é remédio!) e quase nunca pela inimiga moléstia (Nava, 1974, p. 219- 220).

A menção a Francisco de Castro, ao mesmo tempo referido como um "bravo" e "a imagem da brandura e da suavidade", ao lado de personalidades histéricas, impulsivos, exibicionistas e médicos, inclui no comentário do memorialista o discurso da morte heroica, centrado no modelo helênico do sacrifício do guerreiro trágico e virtuoso, ainda jovem, em combate com a morte:

Contou-nos a mesma história, com os mesmos detalhes, da doença e morte do pai. Aloysio acompanhava-o na visita a um doente de peste quando este tem um acesso de tosse e projeta grande quantidade de secreção sobre a face do médico que se curvava para ascultálo. "Vi a face e as barbas do Mestre perladas de catarro" - disse-nos Aloysio, descrevendo a cena. O que se seguiu foi rápido e trágico. Seu pai morreu também, em dias, de uma pneumonia pestosa. [...] Era, no fundo, um duro, e lembro-me bem de uma frase de Aloysio Castro quando ele contou-me, certa vez, detalhes das lutas do pai. Quando ele me falou do encarniçamento com que se batera Francisco de Castro, não pude calar minha surpresa, dizendo que nunca poderia realizar o Divino Mestre metido em tais lances. "Professor, tudo isso me deixa assombrado porque eu fazia de seu pai a imagem da brandura e da suavidade!" "Decerto, decerto, meu bom Nava. Meu pai era a imagem da brandura e da suavidade, era. Mas tocado em seus direitos, reagia como uma fera!" (Nava, 1974, p. 219- 220, grifo do autor).

Se o Dr. Francisco de Castro adoeceu e morreu no exercício da profissão, o mesmo teria sucedido, em 1911, a uma "criatura fraca, esgotada por dois concursos, pelo excesso de trabalho", o "moço doutor", pai de Pedro Nava (1974, p. 386): "Assim é que naquele 30 de junho ele foi ver, na Rua Honório, uma criança com difteria. Àquele frio e àquela umidade com que às vezes o Rio capricha e que eram nefastos ao seu peito amarrado pela asma". Ernst Becker (1973, p. 4-5 Apud Seale, 1995, p. 597) ponderou que a sociedade é e sempre tem sido um sistema simbólico de ação, uma estrutura de costumes, estatutos e comportamentos à maneira de papéis estipulados, designados para atuar como veículos do heroísmo terreno de um sistema heroico-mítico, ao qual as pessoas serviriam para conquistar um sentimento de valor primário.

De acordo com Seale (1995, p. 597), o discurso profissional sobre a morte concederia 
oportunidades para uma forma de heroísmo peculiarmente adaptada às condições da sociedade contemporânea. Nesse discurso, existe a retórica do cuidado, dedicação e preocupação com os outros. Adicionalmente, a tradicional ênfase na coragem em face de perigos externos, torna-se coragem para explorar e expressar o ser à morte, situando-o dramaticamente na vida cotidiana. No caso de uma identidade feminina, morrer jovem implica perpetuar a memória da beleza:

Tudo que ele achara estranho na família sempre sumida, nas bizarrices do comportamento da moça - era a consciência de que havia ali uma condenada à morte que levou sua vida aos limites da conservação de sua imagem de juventude poderosa. Quando viu que a moléstia ia desfigurá-la, aviltar-lhe o corpo maravilhoso e a cabeça divina - retirouse em beleza e foi ao encontro dos deuses seus irmãos (Nava, 1983, p. 103).

Segundo o historiador Jean-Pierre Vernant (1991, p. 96), ao referir-se figurativamente à morte, os gregos usavam um nome masculino: Tânatos. A figura masculina de Tânatos estaria mais próxima da "bela morte" que, como término ideal de uma vida heroica, implicaria uma imortalidade gloriosa no mundo grego. Já as personificações femininas da morte, Górgona e Ker, estão mais próximas da repulsão e do horror, mobilizados na transformação dos seres vivos em despojos ou cadáveres, nos termos de Pedro Nava (1974, p. 21): "frágeis na carne provisória e indefectíveis na podridão final". Nos ritos funerários, o "status" do morto, da "bela morte", na figura de Tânatos, por inúmeras variações, consubstancia um modo de presentificar o falecido entre os vivos. Esta estratégia social visa civilizar e negar a morte pela transformação do falecido e, particularmente, do temor à morte e aos mortos, em parte do passado da polis (um passado tornado continuamente presente para o grupo por meio da memória coletiva).

Górgona e Ker não são imagens da morte que os vivos celebrem e relembrem; antes, representariam uma confrontação direta da morte: para Vernant (1991, p. 97), elas são a própria morte, o domínio além da última fronteira, que não pode ser vislumbrado nem expresso por nenhum discurso. Existem, no entanto, figurações femininas da morte, como esfinges, harpias e sereias, cujo fascínio e sedução se combinam ao espanto e à angústia, em planos nos quais Tânatos e Eros interagem, e a figura da morte divide obscura fronteira com a atração sexual.

$\mathrm{Na}$ Antiguidade grega, morte e velhice caminhavam juntas. Morrer jovem é também escapar ao processo de envelhecer. Posto que a condição humana não é só mortal mas, como toda vida terrena após o florescer de sua juventude, sujeita à debilitante ação do tempo, o sentido do heroico no mundo grego é de ordem metafísica e o legítimo desígnio da luta heroica nada tem a ver com necessidades práticas e prestígio social, mas com o desejo de fugir da morte e da velhice, não importa quão inevitáveis sejam (Vernant, 1991, p. 57-59). Em feitio barroco, a descrição dual de Dona Maria Cândida Pinto de Moura retrata a "atividade paciente" do Tempo:

Lembro-me ainda dessa velha tia que ia muito a Juiz de Fora [...] Sempre aparecia em casa de minha avó. Eu conhecia seu retrato do álbum da 
sala e custava-me a entrar que a soberba moça da fotografia e a feiticeira que nos visitava, mais enrugada que um maracujá de gaveta, pudessem ser uma e mesma pessoa. Eu não suspeitara ainda da existência do Tempo e de sua atividade paciente, companheira da Doença paciente e da Morte paciente (Nava, 1974, p. 119, grifo do autor).

As narrativas e reflexões de Pedro Nava sobre a doença e a morte coadunam-se a um modelo de humanização das ciências médicas, em um discurso singularizado pela erudição.

\section{Um discurso humanista para "reminiscências médicas"}

Nas Memórias, Pedro Nava discorreu sobre a doença e a morte fixando-as em quadros gerais ("a seca de 77 e o seu cortejo de horrores", "a epidemia de gripe chamada 'espanhola'" e o "resultado no número de mortos e feridos" na Revolução de 1930); atendo-se ao relato de casos singulares, por meio de abordagens descritivas, nosológicas e sindrômicas, mas também históricas:

se olharmos numa crítica retrospectiva o que foi o tratamento da gripe naquela época. [...] Além dos sofrimentos da doença - vinham os da panaceia: zoeiras nos ouvidos, vertigens, surdez, urinas de sangue, vômitos. Não tinha importância. Estava nos livros (Nava, 1976, p. 202).

Doença e morte são temas radicados nas lembranças de infância do memorialista:

Desde cedo acordei para esse ambiente de doença e prestei atenção nos vidros dos remédios, nos rótulos, nas coberturas do papel plissado e amarrado em torno às rolhas, nas empolas transparentes, brancas, amareladas, esfumaçadas ou azuis. Brincava com calendários, agendas, bulas e com as figuras coloridas, brindes do Laboratoire Deschiens. Ouvi e guardei palavras cabalísticas, para mim sem sentido, mas cheias de sonoridade mágica, de entressonhada poesia - como esparadrapo, alcanfor, timpanismo, guaiaco, furfurol, gonorreia e clitóris. Prestei sempre a maior atenção ao meu próprio sofrimento, assistindo-o e estudando-o nas minhas moléstias infantis - florescências da catapora, incêndios do sarampão, estrangulamentos das amigdalites, tratadas com pinceladas saborosas de mel rosado e no fim, o pus estourando e dando, de repente, aquele gosto de esgoto logo coberto pelo azedo do vômito. Os dias de doença, passava-os ouvindo histórias da Rosa ou na janela, vendo o dia amarelo (Nava, 1974, 274).

A formação médica de Pedro Nava e sua postura profissional certamente moldaram a composição de seus escritos. Na entrevista a Edmílson Caminha (1995, p. 44), ele explicou um de seus recursos composicionais na redação das Memórias: "Tomo nota das coisas que me importam, numa série de cadernos. Depois eu corto aquilo como fichas - tenho o cuidado de escrever só de um lado da folha, para depois cortar". Ao mencionar essa estratégia, Paulo 
Penido recordou como o memorialista elaborava as fichas de anamnese em consultório:

Certa feita a Julieta, a filha do Drummond deu uma entrevista dizendo que Nava foi um dos primeiros especialistas a tratar reumatismo com palavras. E é verdade. O Nava me dizia: Olha, Paulo, é muito mais importante você conversar com o paciente, levantar o espírito dele na hora em que está diante dele, procurar tirar do doente os seus problemas, do que simplesmente receitar um remédio. E ele anotava na ficha do doente várias informações adicionais: que tinha um filho problemático, um marido que tinha isso, que tinha aquilo, enfim, as preocupações existenciais do cliente. Quando o doente voltava para a nova consulta, o Nava perguntava: E como vai aquele seu parente assim, assim e tal. O doente ficava impressionado. Hoje os médicos são de uma frieza enorme. Mas eu confesso que na época não entendi aquilo que o Nava fazia. Eu achava que era um carisma natural dele. Eu mesmo nunca fiz isso. [...] mas eu não diria que ele era um psicólogo. Ele era mais um grande conversador. Ele levantava a bola do doente. Ele não queria saber de nada que fosse para baixo, queda, negativismo. Sempre dizia algo com o objetivo de soerguer o paciente (Penido, 1998, p. 30-31).

A atitude de Pedro Nava para "soerguer o paciente" espelha uma tendência com origem nos Estados Unidos e no Reino Unido na primeira metade do século XX, em resposta ao rígido sistema médico de ensino que havia imperado por décadas no Ocidente. $O$ historiador Joseph Patrick Byrne (2019, p. 202) considera que esta tendência de humanização da medicina e avanços no currículo educacional significava interesse pelo paciente, e não só pela doença de que era portador.

Na tradição preponderante até o século XIX, os médicos eram ensinados que a comunicação com o paciente deveria ser estritamente objetiva e impessoal. Tal orientação começou a mudar sob o novo modelo que encorajava a interação emocional e intelectual com o doente. Conhecer o contexto em que ocorria a doença e seu significado na vida pessoal, familiar e social do paciente era necessário para um diagnóstico e tratamento bem-sucedidos. Dados como relações interpessoais, profissão, cultura e classe social passaram a ser valorizados na anamnese.

Sobre a questão da morte, em específico, o pensamento de Pedro Nava reporta às ideias do médico húngaro Michael Balint (1896-1970). De acordo com Andrew Elder (1996, p. 111), Professor honorário de Medicina geriátrica da Universidade de Edimburgo, Balint apontou uma nova perspectiva da relação entre médico-paciente, ao considerar também as expectativas e reações do médico (por vezes exausto e frustrado) diante dos pacientes e de seus problemas particulares:

Durante os longos anos de vinculação com o paciente, o clínico geral adquire gradualmente uma grande massa de detalhes importantes. Conhece os antecedentes do doente, ou vários membros da família, frequentemente várias gerações, o tipo de pessoas que constituem suas amizades, a loja, escritório ou fábrica em que trabalha, a rua 
ou vizinhança em que vive [...] seus antecedentes de trabalho, como conheceu a esposa e que tipo de filhos têm. Mas estes são os fatores de menor importância. [...] o paciente sabe quanta ajuda e que tipo de ajuda pode esperar de seu médico (Balint, 1988, p. 216).

Pedro Nava define seu pensamento sobre a morte, como médico e autor, sem se eximir de comentar a influência da experiência pessoal e da carga afetiva das recordações íntimas:

Na mesa-redonda que se seguiu à apresentação de Poliedro, uma intelectual argentina interpelou Nava sobre o sentimento da morte, tão presente no que escrevia, e ele revelou, com naturalidade: - É um sentimento profundo que vem da minha vida, que vem da experiência da minha infância. Isso me marcou demais. Vemos morrer muita gente, participamos dessas mortes, de modo que esse assunto é uma preocupação constante para os médicos que tomamos parte nisso. Parte sentimental. Assistir a essas situações, ver a doença, ver a morte marcam profundamente o médico que tem sensibilidade. Em alguns, acaba com qualquer tipo de sentimento; em outros, apura-o, aprimora-o. Sinto isso dolorosamente, e tudo o que escrevo está impregnado disso, de algumas coisas a que assisti na infância e da repercussão emocional da minha profissão sobre a minha pessoa (Penido, 1998, p. 222).

Balint destacou que os médicos têm atitudes e convicções próprias relativas à doença, ao sofrimento, ao envelhecimento e à morte, além de competências e limitações particulares em face aos relacionamentos humanos, tal como seus pacientes (Elder, 1996, p. 111). A profissão de médico certamente ajudou o memorialista a reconstituir com percepção apurada um quadro narrativo-descritivo sobre a morte e a doença, compreendendo questões culturais, históricas, religiosas e sociais sobre, por exemplo, a dor, o corpo, a melancolia e a sexualidade:

É sempre muito interessante para o médico observador verificar a posição e as reações obscura do psiquismo dos doentes, com relação aos remédios e tratamentos que lhes são impostos. [...] A ideia de expulsão sendo aproximável, por analogia, à de purificação, não será possível colocá-las nas origens da preferência universal pelos tratamentos hidrominerais? Parece. E sendo assim, uma cura em Caxambu, Poços de Caldas ou São Lourenço assume o mesmo aspecto mágico das velhas cerimônias lustrais que repontam na vida de todos os povos, sob a forma do banho ritual, da aspersão litúrgica, do batismo. E este, mais do que tudo, porque é a cura das curas contra a força e o espirito de Satanás - o pior "corpo estranho" que pode nos penetrar. [...] Se a noção do "corpo estranho" que é mister retirar para obter a cura é decisiva na aceitação das intervenções cirúrgicas, concorre no mesmo objetivo a ideia sacrificial e expiatória, inseparável do complexo de culpa e da concepção da moléstia como castigo divino (Nava, 2003, 47-53).

Por vezes, Pedro Nava é capaz de conciliar, em um mesmo excerto, abordagens variadas de um assunto. Ele pode associar diferentes códigos de leitura acerca de um tema, 
expor perspectivas divergentes ou pontos comuns. Assim, a noção de "moléstia" é perscrutada em domínios como a antropologia e a psicanálise, ao discutir quando a "cura assume o mesmo aspecto mágico das velhas cerimônias lustrais que repontam na vida de todos os povos"; e abordada no domínio do discurso simbólico, na referência à "concepção da moléstia como castigo divino". No plano dos métodos de aprendizagem e formação cultural, certos episódios são narrados como anedota:

- Pode parar, Amarante, que o homem está morto!

- Com'é cocê sabe?

- Porque Miguel Ângelo não me engana...

Todos pensaram que o Egon estava divagando... Ele teve de explicar àquelas cabecinhas de médico que referia-se à flexão plantar do primeiro dedo que é tanatognomônica e que caracteriza o dito "pé de cadáver". Que ele vira o mesmo se constituir e que...

- Mas o que tem? Miguel Ângelo com isto.

- Tem porque ele representou este pé no Cristo morto da sua Pietá com realismo espantoso. Até que o sinal devia ter seu nome...

Os colegas riram com superioridade daquela besteira do Egon querendo dar nome dum "artista" a coisa séria como é um sinal de morte (Nava, 1983, p. 23, grifo do autor).

Em sua origem, aplicação à prática e à educação médica, a medicina humanística foi concebida como campo interdisciplinar, cingindo as ciências humanas, as ciências sociais e as artes. As ciências sociais e as humanidades permitiriam ao profissional médico entender como biociência e medicina se estabelecem no contexto cultural e social, as vias pelas quais a cultura interage com a experiência individual da doença, e o modo como a medicina é praticada. À literatura e às artes caberia desenvolver as capacidades de observação, análise, autorreflexão e empatia (Byrne, 2019, p. 202). Pedro Nava expôs tal ideia em "A Medicina de Os Lusíadas":

Múltiplas são as fontes de que se serve o historiador de nossa Arte para tratar das suas vicissitudes dentro da evolução do pensamento humano. História geral, cronologia, sociologia, filologia, linguística, arqueologia e o estudo dos clássicos da anatomia, da fisiologia e da patologia são fontes de investigação a cujo lado devemos colocar como manancial inesgotável de informações as criações da pintura, da escultura, da arquitetura e da literatura universais (Nava, 2004, p. 15-16).

Pedro Nava defendeu esse ideal de humanização do profissional médico nas Memórias e nos textos literários-biográficos sobre a Medicina, com um discurso de viés historicizante, que refletia a riqueza cultural de influências de um modelo pensado como constructo intelectual.

\section{Conclusão}

Com estilo peculiar e conhecimentos de fontes diversas, Pedro Nava (1974, p. 39) torna literário o ato de rememorar o passado: "Parece impossível sua evocação completa porque de 
coisas e pessoas só ficam lembranças fragmentárias". Entrevistado por Lourenço Dantas Mota, para o jornal O Estado de São Paulo em 15 de fevereiro de 1981, ele sublinhou a influência da Medicina em sua obra. Além do exercício profissional, a literatura seria outra via de expressão do saber clínico e cultura médica, acumulados "desde cedo" pelo convívio com o Dr. José Nava:

Eu tive uma vida médica muito intensa. Fui professor de mais de uma faculdade, sou membro da Academia Nacional de Medicina, tive uma atividade clínica muito grande. Posso dizer hoje - porque já passou que fui um médico de sucesso no Rio de Janeiro. E não gostava que suspeitassem da arte literária em mim, achando que isso prejudicaria a imagem do médico. E prejudica... Existe sim, esse preconceito e foi usado contra mim. Os meus colegas têm a gentileza de espalhar que eu não cuido mais de medicina, que só cuido de literatura, que sou só um literato... Foi o exercício médico, não a medicina que me afastou da literatura, porque sou médico em qualquer circunstância. As minhas memórias são cheias de reminiscências médicas. Sente-se ali que o médico está falando. O meu processo é um processo clínico... A descrição dos tipos, por exemplo. Aprendi a olhar, a ver como médico. Temos de usar nossos sentidos de uma maneira absoluta, de tirar deles tudo o que podem render. Modéstia à parte, sei observar... Não dissocio o médico do literato, não dissocio nada na minha obra. Tenho uma obra escrita em medicina, que é muito grande. São cerca de 300 trabalhos publicados... Estou encadernando esses trabalhos e já tenho dois volumes que vou dar ao Museu de Literatura para os críticos verem se escrevo bem como médico, como eles dizem que escrevo como literato (Nava, 1981).

Examinar os temas da morte e da doença na obra do memorialista brasileiro pressupõe perspectiva interdisciplinar, visto que Pedro Nava combina referências simultâneas a diversos campos das ciências e das artes. Entre os possiveis discursos que estruturam as concepções de morte e doença nos escritos do autor, estaria o discurso institucional contemporâneo atento aos sentimentos do paciente e da família na delimitação do quadro clínico e das condutas a seguir.

O Anfiteatro da Policlínica Geral do Rio de Janeiro, criado "para receber médicos e estudantes interessados nas 'Conferências de Prática Reumatológica'", conforme Geraldo Guimarães da Gama (2003, p. 30) e Paulo Penido (1998, p. 28), foi "instalado com dinheiro do bolso dele, tão grande a importância que ele dedicava às discussões médicas com os colegas" - fato que recorda a criação de grupos de estudo clínico por Michael Balint, nos anos 50.

O discurso da doença como metáfora é extenso nas Memórias, e surge em episódios como o que relata a viagem de Pedro da Silva Nava (avô homônimo do memorialista) à Europa, em companhia da mulher, Dona Ana Cândida e do casal Ennes de Souza, em meados de 1874:

Da França foram para Portugal, onde nova e terrivel aventura daria os primeiros cabelos brancos a um Ennes de Souza de vinte e sete anos. Ele viajava com a mulher - carro aberto e cantando pelos caminhos 
d'El-Rei, entre Arruda dos Vinhos e Lisboa, quando viram uma pobre manca com seu bordão, na longa estrada sob o sol a pino. Recolheramna. Conversa vai, conversa vem e ela diz, com toda simplicidade, que demandava a capital para tratar-se da sua gafa. E mostrou as marcas foscas da pele e as mãos ressecadas e encolhidas como garras. Ennes de Souza foi estoico, trouxe a mendiga até Lisboa, mas a aflição de ver sua mulher roças as saias nas da infeliz foi tamanha, que dum dia para o outro grisalhou nas têmporas e nos bigodes que ele tinha espessos e usava caídos (Nava, 1974, p. 61).

As formas heroicas do discurso sobre a morte são tão variadas quanto as narrativas que as ensejam e contêm mitos essenciais da Antiguidade clássica: a morte do herói belo, jovem e probo. Assim, "levado pela mão da 'velha dama insaciável' [...] a 31 de maio de 1880, aos trinta e cinco anos [...] Pedro da Silva Nava pesou nos braços da amada com a violência e a densidade marmóreas do Cristo da Pietà e rolou no tempo que não conta" (Nava, 1974, p. 77).

Este discurso pode revestir-se de aspectos ficcionais, ao designar pessoas por nomes metafóricos e aludir a imagens das artes, história e literatura. A descrição do médico Aloysio de Castro, feita por associação com "retratos" ilustres, como o médico Paul Georges Dieulafoy (1839-1911), o escritor Edmond Rostand (1868-1918) e o estadista Charles de Morny (18111865), denotam a filiação ao estilo descritivo de Marcel Proust ao compor um personagem:

com duas semanas de doença, os médicos chamaram em conferência, O Dr. Aloysio de Castro. Ele entrou magro, elegante, a face ebúrnea, bigodes noturnos, a calva principiando e com aquela atitude decorosa e perfeita que faziam dele o que identifiquei mais tarde, como sendo uma mistura dos retratos do Doutor Dieulafoy, de Edmond Rostand e do Duque de Morny (Nava, 1974, p. 387).

Pensadas no âmbito dos tópicos prioritários da obra naviana, morte e doença tendem a ser referidas pelo memorialista ao lado de temas orbitais recorrentes, a exemplo do suicídio e do envelhecimento, uma das preocupações de Pedro Nava segundo Paulo Penido (1998, p. 229): "examinava sem parar mãos, pés e pernas em busca das 'marcas de decadência' e do que rejeitava como 'velhice repugnante'". O temor de uma velhice incapacitante reporta ao enfoque que Stefano Allievi (2014) atribuiu ao discurso da "morte rinviata" (que deve ser prorrogada).

O discurso que aborda os costumes e a história da Medicina percorre o plano biográfico e autobiográfico das Memórias no relato da vida cotidiana; do progresso técnico; da tradição interpretativa; das esperanças e das crenças; da lembrança dos mortos

envolta com crenças atávicas, complexos animistas e pânicos metempsicósicos. Sem reencarnação integral, mas aparecendo no fim de certos risos, no remate de dados gestos, na possiblidade das mesmas doenças, na probabilidade de morte idêntica (Nava, 1974, p. 21);

e na intenção de homenagem: 
Tenho os apontamentos da "conduta do legista", feitos por meu Pai e neles, quando sexto-anista da Faculdade, estudei muita coisa de Medicina Judiciária. Foi assim, com sua lembrança, que me enfronhei nas técnicas do exame pericial dos cabelos, sangue, esperma, mecônio, massa cerebral e matérias fecais. Como por sua voz aprendi as medidas de Oesterlin, a fórmula do reativo de Florence, o reconhecimento das manchas pelo método de Orfila, Galippe e Mansuino, a identificação do passatempo súbito pela docimasia hepática de Lacassagne, e os processos de lcard para a tanagnose. Lições sobre a Morte, vindas de além da vida. Sua lembrança, sua lição (Nava, 1974, p. 385).

Pedro Nava divisou ligações fecundas entre a memória íntima e a memória coletiva na observação de aspectos históricos e sociológicos da realidade; na alusão às culturas erudita e popular ou "na linha da aplicação prática das teorias de mestre Freud". Para relatar o passado, busca reconstituir e descrever o contexto, por exemplo, de uma época "temente das câmaras de sangue, dos catarros e do estupor" ou entender as influências que moldaram uma personalidade:

O digno militar, velho aluno de Benjamim Constant, tinha ideias próprias onde se combinavam perfeitamente postulados positivistas, revelações da teosofia e prescrições místico-sanitárias da Christian Science. Era admirador do Padre Kneipp, devoto de Raspail, sequaz das teorias de Hahnemann e infenso à alopatia. Saindo destas bases, era inevitável sua crença numa panaceia (Nava, 1974, p. 48).

Sem dissociar "a imagem do médico" dos discursos do literato e do memorialista, os escritos de Pedro Nava emolduram inestimável acervo de informes e relatos sobre a Medicina, a morte e a doença, promissor para os campos das Ciências Humanas e Sociais.

\section{Referências Bibliográficas}

ALLIEVI, Stefano. L'uomo e la morte in Occidente: verso um nuovo paradigma interpretativo. In: VIAFORA, Corrado; MARIN, Francesca (orgs.). Morire altrove: La buona morte in um contexto interculturale. Milano: Franco Angeli, 2014. p. 49-71.

ARIĖS, Phillippe. História da Morte no Ocidente: Da Idade Média aos nossos dias. Tradução Priscila Viana de Siqueira. Rio de Janeiro: Ediouro: 2003. 312 p.

BALINT, Michael. O médico, seu paciente e a doença. São Paulo: Livraria Atheneu, 1988. 331 p.

BODEI, Remo. L'epoca dell'antidestino. In: BODEI, Remo; MONTI, Daniela (eds.). Che cosa vuol dire morire: sei grandi filosofi di fronte all'ultima domanda. Torino: Einaudi, 2010. p. 53-78.

BYRNE, Joseph Patrick. Societal Factors in Health and Medicine. In: ENGS, Ruth Clifford (ed.). Health and Medicine through History: From Ancient Practices to 21st-Century Innovations. Santa Barbara: Greenwood, 2019. p. 199-204. 
CAMINHA, Edmílson. Palavra de Escritor. Brasília: Thesaurus Editora, 1995. 238 p.

CANDIDO, Antonio. Poesia e ficção na autobiografia. In: CANDIDO, Antonio. A educação pela noite \& outros ensaios. São Paulo: Editora Ática, 1989. p. 51-69.

CARRARA, Sérgio. A difícil medicalização do mal: castigos, doenças e troféus. In: CARRARA, Sérgio. Tributo à Vênus: a luta contra a sífilis no Brasil, da passagem do século aos anos 40. Rio de Janeiro: Editora FIOCRUZ, 1996. p. 133-164.

DOLLIMORE, Jonathan. Death, Desire and Lost in Western Culture. Londres: Routledge, 1998. $284 \mathrm{p}$.

ELDER, Andrew. Moments of Change. In: SPILLIUS, Elizabet Bott. Michael Balint: Object Relations Pure and Applied. Londres: Routledge, 1996. p. 111-129.

EM TEMPO de Pedro Nava. Direção: Fernando Sabino e David Neves. Rio de Janeiro: Bemte-vi Filmes, 1974. Curta-metragem, cor, 16 e 35 mm (10 min.). Disponível em: https://www. youtube.com/watch?v=LKpoZsidQe4. Acesso: 26 dez. 2019.

GAMA, Geraldo Nogueira da. Pedro Nava, o Médico. In: NAVA, Pedro. Território de Epidauro: Crônicas e Histórias da História da Medicina. Cotia, SP: Ateliê Editorial, 2003. p. 17-45.

GARCIA, Celina Fontenele. A escrita Frankenstein de Pedro Nava. Fortaleza: UFC Edições, 1997, $222 \mathrm{p}$.

GUIMARÃES, Raquel Beatriz Junqueira. Pedro Nava, leitor de Drummond: a memória, os retratos, a leitura. Em Tese. Belo Horizonte, v. 4, p. 29-37, dez. 2000. Disponível em http://www. periodicos.letras.ufmg.br/index.php/emtese/article/view/2165/2103. Acesso: 26 dez. 2019.

HAYASIDA, Nazaré Maria de Albuquerque; ASSAYAG, Raquel Helena; FIGUEIRA, Isa; MATOS, Margarida Gaspar. Morte e luto: competência dos profissionais. Revista Brasileira de Terapias Cognitivas. Rio de Janeiro, v. 10, n. 2, p. 112-121, dez. 2014. Disponível em: http://dx.doi. org/10.5935/1808-5687.20140017. Acesso em: 26 dez. 2019.

LAFONTAINE, Céline. La société postmortelle: la mort, l'individu et le lien social à l'ére des technosciences. Paris: Seuil, 2008. 125 p.

LAFONTAINE, Céline. The Postmortal Condition: From the Biomedical Deconstruction of Death to the Extension of Longevity. Science as Culture. Londres, v. 18, n. 3, p. 297-312, nov. 2009. Disponível em: https://www.tandfonline.com/doi/ abs/10.1080/09505430903123008?journalCode=csac20. Acesso em: 26 dez. 2019.

LIMA, Nísia Trindade. Petrópolis como ponto de encontro e inspiração. Anais da ANM. Rio de Janeiro, v. 190, n. 2, 2019. Disponível em: http://www.anm.org.br/anais/AnaisVolume-190-2-2019.pdf. Acesso: 26 dez. 2019.

NAVA, Pedro. Baú de Ossos. 3a ed. Rio de Janeiro: Livraria José Olympio Editora, 1974. 392 p.

NAVA, Pedro. Chão de Ferro. Rio de Janeiro: Livraria José Olympio Editora, 1976. 408 p.

NAVA, Pedro. Beira-Mar. 2ª ed. Rio de Janeiro: Livraria José Olympio Editora, 1979. 408 p. 
NAVA, Pedro. "Quando vamos pescar uma coisa nesse oceano sem fundo que é a memória, o anzol já vai molhado do presente". [Entrevista cedida a] Lourenço Dantas Motta. O Estado de São Paulo. São Paulo, ano 1, n. 36, 15 fev. 1981. Caderno Cultura, p. 9.

NAVA, Pedro. O Círio Perfeito. 5a ed. São Paulo: Ateliê Editorial, 1983. 576 p.

NAVA, Pedro. Revivescências. In: NAVA, Pedro. Território de Epidauro: Crônicas e Histórias da História da Medicina. Cotia, SP: Ateliê Editorial, 2003. p. 47-54.

NAVA, Pedro. A Medicina de Os Lusíadas e outros textos. Cotia, SP: Ateliê Editorial, 2004. 101 p.

NEUBARTH, Fernando. Importa a Memória. In: NAVA, Pedro. Território de Epidauro: Crônicas e Histórias da História da Medicina. Cotia, SP: Ateliê Editorial, 2003. p. 11-13.

PANICHI, Edina Regina P. A morte como protagonista. Soletras. Rio de Janeiro, ano 7, n. 14, p. 46-54, jul./dez. 2007. Disponível em: https://www.e-publicacoes.uerj.br/index.php/soletras/ article/viewFile/4716/3479. Acesso: 26 dez. 2019.

PANICHI, Edina. Cem anos cravados na memória? Folha de Londrina. 04 de junho de 2003. Disponivel em: https://www.folhadelondrina.com.br/folha-2/cem-anos-cravados-namemoria-449186.html. Acesso em: 23 mai. 2020.

PANICHI, Edina; CONTANI, Miguel L. Pedro Nava e a construção do texto. Londrina: Eduel, 2003. 166 p.

PENIDO, Paulo (org.). O Bicho Urucutum. São Paulo: Ateliê Editorial, 1998. 240 p.

PENIDO, Paulo. Apresentação. In: NAVA, Pedro. A Medicina de Os Lusíadas e outros textos. Cotia, SP: Ateliê Editorial, 2004. p. 9-11.

PENIDO, Paulo. Os cadernos de meu tio. In: NAVA, Pedro. Viagem ao Egito, Jordânia e Israel. $2^{\underline{a}}$ ed. Cotia, SP: Ateliê Editorial, 2004, 72 p, p. 7-11.

POE, Edgar Allan. A filosofia da composição. In: POE, Edgar Allan. Allan Poe: Poesia e Prosa. Tradução de Oscar Mendes e Milton Amado. São Paulo: Ediouro, 2000. p. 407-414.

SCLIAR, Moacyr. Do Mágico ao Social: Trajetória da Saúde Pública. São Paulo: Editora Senac, 2002. $160 \mathrm{p}$.

SEALE, Clive. Heroic Death. Sociology. Londres, v. 29, n. 4, p. 597-613, nov. 1995. Disponível em: https://www.jstor.org/stable/42855607. Acesso em: 26 dez. 2019.

SONTAG, Susan. Doença como Metáfora/ Aids e suas Metáforas. São Paulo: Companhia de Bolso, 2007. $168 \mathrm{p}$.

SOUZA, Eneida Maria. Pedro Nava se desenha. In: SOUZA, Eneida Maria; MIRANDA, Wander Mello (Orgs.). Arquivos Literários. São Paulo: Ateliê Editorial, 2003.

VALE, Vanda Arantes. A obra de Pedro Nava como contribuição ao estudo da história da medicina brasileira (1890-1940). In: ENCONTRO REGIONAL DE HISTÓRIA, 13. 2002, Belo Horizonte. Anais [...]. Juiz de Fora: Clio Edições Eletrônicas, 2002a. p. 103-121. Disponível em: http://www.ufjf.br/clioedel/files/2009/10/COD02003.pdf. Acesso: 26 dez. 2019. 
VALE, Vanda Arantes. A organização da medicina científica em Juiz de Fora - Baú de Ossos. In: ENCONTRO REGIONAL DE HISTÓRIA, 13. 2002, Belo Horizonte. Anais [...]. Juiz de Fora: Clio Edições Eletrônicas, 2002b. p. 99-105. Disponível em: http://www.ufjf.br/clioedel/ files/2009/10/COD02003.pdf. Acesso: 26 dez. 2019.

VALE, Vanda Arantes. A Doença nos Escritos de Pedro Nava. In: NASCIMENTO, Dilene Raimundo; CARVALHO, Diana Maul; MARQUES, Rita de Cássia (orgs.). Uma História Brasileira das Doenças. Volume II. Rio de Janeiro: Mauad X, 2006. p. 92-115.

VASCONCELLOS, Eliane. De bissexto a contumaz. In: VASCONCELLOS, Eliane (org.). Inventário do Arquivo Pedro Nava. Rio de Janeiro: Edições Casa de Rui Barbosa, 2001. p. 9-32.

VERNANT, Jean-Pierre, ZEITLYN, Froma (ed.). Mortals and Immortals: Jean-Pierre Vernant Collected Essays Princeton: Princeton University Press, 1991. 341 p.

WALTER, Tony. The Revival of Death. Londres: Routledge, 1994. 240 p.

WALTER, Tony. What death means now: Thinking critically about dying and grieving. Bristol: Police Press, 2017. 146 p.

Recebido em: 16 de janeiro de 2020

Aprovado em: 13 de maio de 2020 